\title{
Isavuconazole for the treatment of invasive aspergillosis and mucormycosis: current evidence, safety, efficacy, and clinical recommendations
}

This article was published in the following Dove Press journal:

Infection and Drug Resistance

7 December 2016

Number of times this article has been viewed

\author{
Suganthini Krishnan \\ Natesan ${ }^{1,2}$ \\ Pranatharthi $\mathrm{H}$ \\ Chandrasekar' \\ 'Division of Infectious Diseases, \\ Department of Internal Medicine, \\ Wayne State University, ${ }^{2}$ John D \\ Dingell VA Medical Center, Detroit, \\ MI, USA
}

\begin{abstract}
The majority of invasive mold infections diagnosed in immunocompromised cancer patients include invasive aspergillosis (IA) and mucormycosis. Despite timely and effective therapy, mortality remains considerable. Antifungal agents currently available for the management of these serious infections include triazoles, polyenes, and echinocandins. Until recently, posaconazole has been the only triazole with a broad spectrum of anti-mold activity against both Aspergillus sp. and mucorales. Other clinically available triazoles voriconazole and itraconazole, with poor activity against mucorales, have significant drug interactions in addition to a side effect profile inherent for all triazoles. Polyenes including lipid formulations pose a problem with infusion-related side effects, electrolyte imbalance, and nephrotoxicity. Echinocandins are ineffective against mucorales and are approved as salvage therapy for refractory IA. Given that all available antifungal agents have limitations, there has been an unmet need for a broad-spectrum anti-mold agent with a favorable profile. Following phase III clinical trials that started in 2006, isavuconazole (ISZ) seems to fit this profile. It is the first novel triazole agent recently approved by the United States Food and Drug Administration (FDA) for the treatment of both IA and mucormycosis. This review provides a brief overview of the salient features of ISZ, its favorable profile with regard to spectrum of antifungal activity, pharmacokinetic and pharmacodynamic parameters, drug interactions and tolerability, clinical efficacy, and side effects.
\end{abstract}

Keywords: isavuconazole, aspergillosis, mucormycosis, efficacy, antifungal therapy, novel azole, tolerability, drug interactions

\section{Introduction}

Invasive fungal infections (IFIs) continue to pose a therapeutic challenge in immunocompromised patients. ${ }^{1,2}$ Despite timely and effective antifungal therapy, the mortality from IFI remains significant. ${ }^{3-10}$ This is in part attributed to the potent immunosuppressive chemotherapeutic regimens and aggressive transplant protocols. Invasive aspergillosis (IA) and mucormycosis are the most frequently encountered mold infections in immunocompromised cancer patients and hematopoietic stem-cell transplant recipients. ${ }^{11,12}$ Prophylactic protocols implemented in various institutions have altered the spectrum of invasive mold infections. ${ }^{13}$ Antifungal combination therapies have been tried in refractory mold infections. ${ }^{14}$ Also, there are reports of emerging azole resistance from several institutions around the world. ${ }^{15}$ Antifungal classes currently available for the treatment of IFI include polyenes, azoles, and echinocandins. ${ }^{16,17}$ Each class of antifungal agents has its limitations including side effects, limited spectrum of activity, drug interactions, and lack of oral formulations. One of the most recent additions to the antifungal armamentarium is isavuconazole (ISZ), a novel triazole agent that has shown good clinical efficacy
Correspondence: Suganthini Krishnan Natesan

Division of Infectious Diseases, John D Dingell VA Medical Center, 4646 John R, Room C3917, Detroit, MI 4820I, USA

Tel + I 3 I 35763057

$\mathrm{Fax}+\mathrm{I} 3135761242$

Email skrishn@med.wayne.edu 
against IA and mucormycosis. ${ }^{18-20}$ This article provides an overview of this new agent, data on its efficacy in vitro and in vivo, tolerability, pharmacokinetics (PK), pharmacodynamics (PD), and potential advantages over other agents.

ISZ is the active moiety (BAL4815) obtained when the water-soluble prodrug called isavuconazium (BAL8557), with a very short half-life of $<1 \mathrm{~min}$, is cleaved by plasma esterases (Figure 1). ${ }^{21,22}$

\section{Mechanism of action}

ISZ, like other triazoles, acts by inhibition of the cytochrome P450-dependent 14-alpha-lanosterol demethylase of the fungal cell membrane. This leads to accumulation of toxic cell membrane sterols and inhibition of ergosterol production, an integral component of the fungal cell membrane. Inhibition of fungal growth and replication follows, leading to cell death. ${ }^{23}$ ISZ has been introduced as a broad-spectrum triazole with several advantages when compared with the currently available antifungal agents. As outlined below, several in vitro, in vivo, and clinical trials have validated its potency, efficacy, and safety. ${ }^{24-32}$

\section{In vitro activity}

The in vitro activity of ISZ against several Aspergillus sp. and the Mucorales has been tested extensively using the standardized CLSI methodology to evaluate $\mathrm{MIC}_{50}$ (minimum inhibitory concentration to inhibit $50 \%$ growth), $\mathrm{MIC}_{90}$ (minimum inhibitory concentration to inhibit $90 \%$ of growth), and MFC (minimum fungicidal concentration). ${ }^{33,34}$ Antifungal activity has been demonstrated against various Aspergillus sp. including Aspergillus fumigatus, Aspergillus flavus, and Aspergillus terreus. The $\mathrm{MIC}_{50}$ range was $0.25-1 \mu \mathrm{g} / \mathrm{mL} ; \mathrm{MIC}_{90}$ range was $0.39-4 \mu \mathrm{g} / \mathrm{mL}$. The exception was Aspergillus niger that had a higher $\mathrm{MIC}_{50} / \mathrm{MIC}_{90}$ range of $2-4 \mu \mathrm{g} / \mathrm{mL}$, higher than that reported for voriconazole (VCZ) and posaconazole (POS) (1-2 and $0.5 \mu \mathrm{g} / \mathrm{mL}$, respectively) (Table 1). ${ }^{35,36}$

Given the recent reports of emerging azole-resistant isolates of Aspergillus species, some azole-resistant isolates were tested in vitro. Isolates that exhibited L98, G138, G434C, and Y431C mutations showed pan-azole resistance, including ISZ resistance. However, isolates with the G54 mutation had lower MICs to ISZ compared with POS. ISZ also showed promising antifungal activity against Aspergillus species that were resistant to caspofungin (CFG) or amphotericin B (AMB). Demonstration of this variable susceptibility pattern among azole-susceptible and azole-resistant isolates raises the question about the need for susceptibility testing. ${ }^{37,38}$ Epidemiological cutoff values have been established for ISZ against $A$ spergillus species (reported as $1 \mu \mathrm{g} / \mathrm{mL}$ for $A$. fumigatus, $A$. flavus, and $A$. terreus, $0.25 \mu \mathrm{g}$ for Aspergillus nidulans, and $4 \mu \mathrm{g} / \mathrm{mL}$ for $A$. niger). These values help in detecting non-wild-type isolates with reduced susceptibility to ISZ during screening. ${ }^{38-41}$

The major pathogens in mucorales family include $R h i$ zopus, Rhizomucor, Mucor, Lichtheimia (formerly Absidia), and Cunninghamella. Antifungal agents active against this group of organisms at present are polyenes and selected newer azoles (POS and ISZ).

The susceptibility pattern of these molds $\left(\mathrm{MIC}_{50} / \mathrm{MIC}_{90}\right)$ to ISZ is highly variable, dependent on the species tested, and exhibits a wide range $(0.015 \rightarrow 8 \mu \mathrm{g} / \mathrm{mL})$. On the basis of this observation, susceptibility testing becomes necessary in some clinical situations (Table 2). ${ }^{42-46}$

\section{Combination studies}

The combination of ISZ and micafungin (MFG) resulted in a synergistic interaction in A. fumigatus, A. flavus, A. terreus,

Table I In vitro susceptibilities of Aspergillus sp. to ISZ

\begin{tabular}{lll}
\hline Organism & MIC $_{50}(\mu \mathrm{g} / \mathrm{mL})$ & MIC $_{90}(\mu \mathrm{g} / \mathrm{mL})$ \\
\hline Aspergillus fumigatus & $0.25-1$ & $0.5-2$ \\
Aspergillus flavus & $0.5-2$ & $1-16$ \\
Aspergillus terreus & $0.5-1$ & $0.5-4$ \\
Aspergillus niger & $0.5-2$ & $2-4$ \\
\hline
\end{tabular}

Notes: Data compiled from 35-4I,43-45.

Abbreviations: ISZ, isavuconazole; $\mathrm{MIC}_{50}$, minimum inhibitory concentration to inhibit 50\% growth; MIC $_{90}$, minimum inhibitory concentration to inhibit $90 \%$ of growth.
A

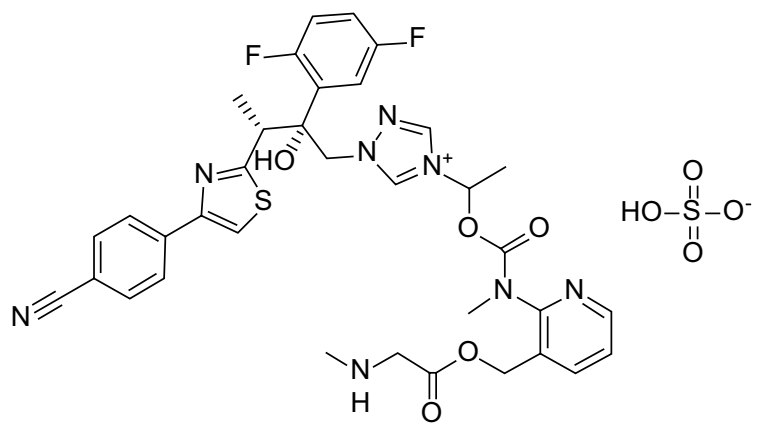

B

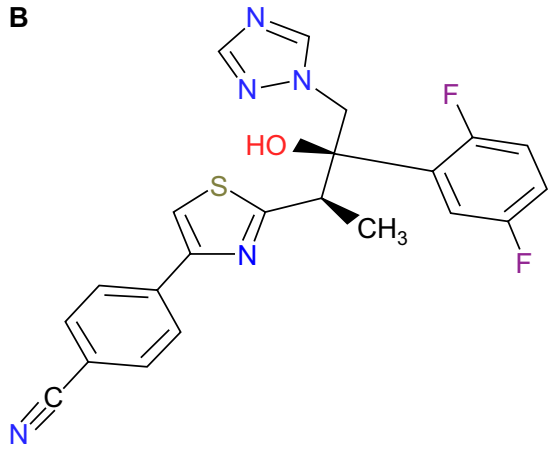

Figure I Structure and chemistry of Isavuconazium (A) and Isavuconazole (B). 
Table 2 In vitro susceptibilities of mucorales to ISZ

\begin{tabular}{lll}
\hline Organism & MIC $_{50}(\mu \mathrm{g} / \mathrm{mL})$ & MIC $_{90}(\mu \mathrm{g} / \mathrm{mL})$ \\
\hline Lichtheimia (Absidia) & $0.5-4$ & $4-8$ \\
Rhizopus & $0.25-4$ & $2-4$ \\
Rhizomucor & $\mathrm{I}-2$ & $8-16$ \\
Mucor & $2-4$ & $8-16$ \\
Cunninghamella & $\mathrm{I}-2$ & $8-16$ \\
\hline
\end{tabular}

Notes: Data compiled from. ${ }^{42,44-46}$

Abbreviations: ISZ, isavuconazole; $\mathrm{MIC}_{50}$, minimum inhibitory concentration to inhibit $50 \%$ growth; $\mathrm{MIC}_{90}$, minimum inhibitory concentration to inhibit $90 \%$ of growth.

and Cunninghamella bertholletiae, and indifferent interactions against Mucor circinelloides, Rhizopus microsporus, and Rhizopus oryzae. The ISZ-AMB combination resulted in antagonism in A. fumigatus, A. flavus, Fusarium solani, and $R$. microsporus but indifferent interaction against Lichtheimia corymbifera, $M$. circinelloides, and $R$. oryzae. The type of ISZ-AMB interaction against $A$. terreus and $C$. bertholletiae appeared to be concentration dependent. Interestingly, the ISZ-MFG combination was found to be concentration and organism dependent (i.e., for C. bertholletiae and L. corymbifera at ISZ concentrations near the MIC, the interactions were synergistic, and at low ISZ concentrations, the interactions were antagonistic). ${ }^{47,48}$ Given the inherent limitations with in vitro combination studies, in vivo studies are needed before any recommendations are made for combination therapy.

\section{Efficacy in vivo (animal models)}

Animal models using ISZ have focused on dose determination, data on PK and PD parameters, and efficacy studies in neutropenic murine models of mucormycosis and IA. Results from these studies have been favorable. ${ }^{49}$ Tissue distribution in male rats was evaluated using radiolabeling technology, after a single intravenous infusion of $3 \mathrm{mg} / \mathrm{kg}$ of ISZ. Quantitative whole-body autoradiography was used for the specific detection of $14 \mathrm{C}$ and $3 \mathrm{H}$ radioactivity, and total radioactivity in blood and plasma was analyzed by liquid scintillation counting. The $14 \mathrm{C}$ label was in the active drug moiety and the $3 \mathrm{H}$ label was in the pro-moiety. Maximum $14 \mathrm{C}$ radioactivity was detected in all tissues at $0.5 \mathrm{~h}$ postadministration. All tissues had good levels, except eye lens, with highest levels found in the adrenal cortex (6.92 $\mu$ g-equiv/g) and liver (6.14 $\mu$ g-equiv/g) with tissue/plasma concentration reported at ratios of 15.2 and 13.5, respectively. High levels of $14 \mathrm{C}$ radioactivity (tissue/plasma ratios $>5$ ) were found in other tissues. Lung-to-brain plasma ratios at $0.5 \mathrm{~h}$ post-dose were 2.28 and 1.86 , respectively. At 144 h, only adrenal medulla and liver contained quantifiable levels ( $>0.02 \mu \mathrm{g}$-equiv/g) of 14C. $3 \mathrm{H}$ radioactivity was widely distributed as well at $0.5 \mathrm{~h}$ and tissue levels declined rapidly, with all tissues containing low to nondetectable $3 \mathrm{H}$ radioactivity by $8 \mathrm{~h}$, except intestinal contents and kidney. Excretion was almost complete within $144 \mathrm{~h}$, with $\sim 80 \% 14 \mathrm{C}$ radioactivity recovered in bile/feces and $20 \%$ in urine. Results from these studies show that ISC is widely distributed in tissue, including the eye and brain. Data appear promising for the treatment of ophthalmic and central nervous system invasive mold infections. ${ }^{50}$

Another in vivo study demonstrated the PD profile of ISZ using a neutropenic murine model of invasive pulmonary aspergillosis (IPA). Ten isolates of $A$. fumigatus isolates (4 Cyp51 wild type and 6 Cyp 51 mutants; MIC of $0.125-8 \mathrm{mg} / \mathrm{L}$ ) were used for infection. Mice were subsequently treated with $40-640 \mathrm{mg} / \mathrm{kg} / 12 \mathrm{~h}$ oral prodrug (BAL8557) for 7 days and efficacy was determined by quantitative aspergillus PCR of lung homogenates. The infection model was uniformly lethal in untreated control mice. PD endpoints included static dose area under the curve (AUC)/MIC and $1 \log 10$ kill AUC/MIC. The results were similar with both $C y p$ wild type and mutant groups. A stasis endpoint was achieved for all isolates with an $\mathrm{MIC}$ of $\leq 1 \mathrm{mg} / \mathrm{L}$ and $1 \log 10$ kill in all isolates with an MIC of $\leq 0.5 \mathrm{mg} / \mathrm{L}$. The static dose range was $65-617 \mathrm{mg} /$ $\mathrm{kg} / 12 \mathrm{~h}$. The corresponding median free drug AUC/MIC was near 5 . The $1 \log 10$ kill dose range was $147-455 \mathrm{mg} / \mathrm{kg} / 12 \mathrm{~h}$ and corresponding median free drug AUC/MIC of 11.1. The results were similar to those reported for other triazoles. ${ }^{51}$

Given reports of azole resistance, the in vivo efficacy of $0.25,1,4,16,64,128,256$, and $512 \mathrm{mg} / \mathrm{kg}$ body weight/ day of the prodrug isavuconazonium sulfate (BAL8557) (ISZ-equivalent doses of $0.12,0.48,1.92,7.68,30.7,61.4$, 122.9 , and $245.8 \mathrm{mg} / \mathrm{kg} /$ day, respectively) administered by oral gavage was studied in an immunocompetent murine model of IA against four clinical $A$. fumigatus isolates: a wild-type isolate and three azole-resistant isolates harboring substitutions in the cyp51A gene: G54W M220I, and $\mathrm{TR}_{34} /$ L98H with EUCAST (European Committee on Antimicrobial Susceptibility Testing) reported ISZ MICs of $0.5,4$, and 8 $\mathrm{mg} / \mathrm{L}$, respectively. The maximum effect (100\% survival) was reached at a prodrug isavuconazonium sulfate dose of $64 \mathrm{mg} / \mathrm{kg}$ for the wild-type isolate, $128 \mathrm{mg} / \mathrm{kg}$ for the G54W mutant, and $256 \mathrm{mg} / \mathrm{kg}$ two times per day (q12) for the M220I mutant. A maximum response was not achieved with the $\mathrm{TR}_{34} / \mathrm{L} 98 \mathrm{H}$ isolates even with the highest dose of prodrug isavuconazonium sulfate $(256 \mathrm{mg} / \mathrm{kg} \mathrm{q} 12)$. For a survival rate of $50 \%$, the effective $\mathrm{AUC}_{0-24} / \mathrm{MIC}_{\text {EUCAST }}$ ratio for ISZ total drug was 24.73 (95\% confidence interval, 22.50-27.18). This study demonstrated that the efficacy of ISZ was dependent on both plasma concentration as well as the ISZ MIC of the fungal isolates. The quantitative relationship between exposure and effect $\left(\mathrm{AUC}_{0-24} / \mathrm{MIC}\right)$ can therefore be utilized to 
maximize the efficacy of ISZ against azole-resistant strains of Aspergillus species. ${ }^{49}$ Therapeutic drug monitoring for ISZ is not indicated at present. Further data are needed before making any final recommendation. Importantly, the above studies showed that ISZ is fungicidal as the observed MFC values were equivalent to the MIC values.

Next, the efficacy of the prodrug isavuconazonium sulfate was evaluated in a neutropenic mouse model of intratracheal infection caused by Rhizopus delemar 99-880 (a clinical isolate grown from brain tissue) with ISZ $\mathrm{MIC}_{100}$ and MFC values of $0.25 \mu \mathrm{g} / \mathrm{mL}$. Male ICR mice were rendered neutropenic by cyclophosphamide $(200 \mathrm{mg} / \mathrm{kg}$ of body weight intraperitoneally [i.p.]) and cortisone acetate (500 mg/ $\mathrm{kg}$ subcutaneously) on days -2 and 3 relative to infection. Mice were then infected intratracheally on day zero, with $2.5 \times 10^{5}$ spores of $R$. delemar 99-880. The prodrug isavuconazonium sulfate at three different doses $(80,110$, and $215 \mathrm{mg} / \mathrm{kg}$ ) was given orally three times daily starting $8 \mathrm{~h}$ postinfection and continued through day 4 . The higher dose of $215 \mathrm{mg} / \mathrm{kg}$ q8h of isavuconazonium sulfate demonstrated enhanced efficacy over that of placebo treatment of mice ( $70 \%$ survival in the isavuconazonium sulfate-treated mice versus $10 \%$ survival for placebo mice), after 21 days. As a high dose of ISZ (215 mg/kg q8h) demonstrated efficacy against $R$. delemar infection, the efficacy of this dose was compared with that of the standard therapy for mucormycosis (high dose of liposomal amphotericin B; LAmB). Eight hours postinfection, treatment with isavuconazonium sulfate (215 $\mathrm{mg} / \mathrm{kg}$ q $8 \mathrm{~h}$, given orally) or LAmB $(15 \mathrm{mg} / \mathrm{kg}$, given once daily through tail vein injection) started and continued through day 4. The primary endpoint for efficacy was the time to clinical disease based on clinical parameters in infected mice. ISZ showed similar efficacy as LAmB. The 21-day survival rates for ISZ, LAmB, and placebo-treated mice were $65 \%, 40 \%$, and $15 \%$, respectively. Treatment of the mice with the prodrug resulted in an approximately 1 log decrease in lung and brain fungal burdens compared with those of placebo-treated controls. This reduction in tissue fungal burden was comparable to that seen in the LAmB-treated group. ${ }^{52}$

\section{PK and PD}

An important strategy utilized to optimize treatment outcomes of an antifungal agent is evaluation of its PD. The PD of ISZ was studied in a neutropenic murine model of IPA, using azole-susceptible and azole-resistant isolates of $A$. fumigatus. The PD target endpoints examined were static dose AUC/ $\mathrm{MIC}$ ratio and the $1 \log 10 \mathrm{killing} \mathrm{AUC} / \mathrm{MIC}$ ratio. The static dose range was $65-617 \mathrm{mg} / \mathrm{kg} / 12 \mathrm{~h}$ and a median free-drug AUC/MIC ratio near 5. The 1 log 10 killing dose range was $147-455 \mathrm{mg} / \mathrm{kg} / \mathrm{q} 12 \mathrm{~h}$ and a median free-drug AUC/MIC of
11.1. Data were similar to that reported for other triazoles. ISZ has also demonstrated post-antifungal effect in vitro and in a neutropenic murine model of invasive candidiasis, with duration ranging from 2 to $5 \mathrm{~h}$ based on serum concentration achieved above MIC. A higher AUC/MIC ratio was associated with an increased survival rate in this model. ${ }^{53-55}$ Human PK parameters have been assessed in healthy adult males using single and multiple ascending dose studies. These studies showed slow elimination (76-104 h), high protein binding to albumin (>99\%), extensive volume of distribution of 450 $\mathrm{L}$, time to maximum absorption of $1.5-3 \mathrm{~h}$, and a high oral availability with no clinically relevant food effect on AUC or plasma concentration at $24 \mathrm{~h}$. PK studies have also demonstrated $\sim 40 \%$ lower clearance in Asian population compared to Caucasians, and a higher volume of distribution with higher body mass index in patients compared to healthy adults. The drug exhibits linear PK and is not removed by hemodialysis as $99 \%$ of drug is bound to protein and $<1 \%$ is excreted in urine. Population PK studies were also performed in adults with mild and moderate hepatic impairment to evaluate clearance of ISZ in this setting. Less than twofold increase in ISZ trough levels was seen in subjects with mild to moderate hepatic impairment compared to healthy controls. Results were similar for both oral and intravenous routes tested. ${ }^{56,57}$ Warn et al evaluated the plasma and renal concentrations of ISZ in a murine model of disseminated candidiasis and concluded that renal concentrations were higher than plasma levels, even after clearance of drug from plasma, the post-antifungal effect lasted $\sim 5$ to 8 $\mathrm{h}$, and the AUC/MIC ratio associated with a $90 \%$ probability of survival in temporarily and persistently neutropenic mice were 270 and 670, respectively. ${ }^{58}$ An open-label study evaluated ISZ as a prophylactic agent in neutropenic patients with acute myeloid leukemia with good results. ${ }^{59}$ Multiple-dose PK tested in healthy subjects demonstrated that the maximum ISZ concentration in the plasma $\left(\mathrm{C}_{\max }\right)$ and AUC increased proportionally to the administered dose. At steady state, the volume of distribution was large and amounted 308-542 L. Measured $\mathrm{C}_{\max }$ values were 2.56 and $2.55 \mu \mathrm{g} / \mathrm{mL}$ after oral and intravenous administration, respectively, which confirmed the bioequivalence of both oral and intravenous formulations of ISZ. ${ }^{60-65}$ Evaluation of PK parameters from phase I and phase III studies from SECURE trial concluded that adequate ISZ levels were achieved in serum and the long elimination half-life of ISZ (terminal phase half-life of 25-31 h) supported once- or twice-daily dosing for clinical trials. ${ }^{66}$ Dose adjustments are, therefore, not required when switching between oral and intravenous formulations, and absorption is not dependent on food or drugs that increase the gastric $\mathrm{pH} .{ }^{67,68}$ Concentration-dependent efficacy was tested in a 
rabbit model of IPA. There was a dose-dependent reduction in fungal burden as indicated by colony counts in the lung and a decline in beta-D glucan and galactomannan levels in the bronchoalveolar fluid. ${ }^{69}$ Another study that analyzed results from phase III SECURE trial found that both length of stay in the hospital and utilization of resources were better with ISZ (9 days) compared with VCZ (19 days), particularly in patients with moderate to severe renal insufficiency. ${ }^{70}$ However, the study population was small and the results were not statistically significant. Therefore, more clinical data are needed before making any conclusions from this study.

\section{Drug interactions}

ISZ has fewer drug interactions in vivo, compared with VCZ and POS. ISZ is a mild to moderate inhibitor of CYP3A4 and a mild inducer of CYP2B6 (Table 3). It differs from other azoles in that it has negligible effect on CYP1A2, CYP2C9, CYP2C19, CYP2A6, or CYP2D6. Dosage adjustment is not needed for warfarin therapy. ${ }^{71}$ Concomitant use of strong inducers (eg, rifampin) or strong inhibitors (eg, Ritonavir) of CYP3A is contraindicated, along with ISZ. ${ }^{72}$ Coadministration of tacrolimus or sirolimus increases the AUC 1.25- and 84-fold, respectively. ${ }^{73}$ Thus, therapeutic drug monitoring of such drugs is indicated with concomitant use of ISZ. Drugs that are $P$-glycoprotein substrates (eg, digoxin, colchicine, mycophenolate) may need dosage adjustment and close monitoring of serum levels to avoid toxicities. ${ }^{74-77}$

\section{Clinical efficacy trials}

ISZ was studied in three phase III trials, one for candidiasis (ACTIVE), one for aspergillosis (SECURE), and one for mucormycosis (VITAL).

\section{ISZ for IA (SECURE trial)}

ISZ received FDA approval based on the results from the SECURE study. This was a global, multicenter, double-blinded, phase III, noninferiority trial that spanned a 7-year period from March 2006 through March 2013. A total of 516 adult patients with proven, probable, or possible invasive mold infections, as defined by the European Organization for Research and Treatment of Cancer/Mycoses Study Group (EORTC/MSG) criteria, were randomized to a 1:1 ratio, and received either isavuconazonium sulfate $372 \mathrm{mg}$ (prodrug; equivalent to $200 \mathrm{mg}$ ISZ; intravenously three times a day for first 2 days, then either intravenously or orally once daily) or VCZ at a dose of $6 \mathrm{mg}$ / $\mathrm{kg}$ intravenously twice daily on day $1,4 \mathrm{mg} / \mathrm{kg}$ intravenously twice daily on day 2 , and then intravenously $4 \mathrm{mg} / \mathrm{kg}$ twice daily or orally $200 \mathrm{mg}$ twice daily from day 3 onward. The primary endpoint was all-cause mortality at day 42, in patients who received at least one dose of the study drug (ITT, intentionto-treat population), using a noninferiority margin of $10 \%$. All-cause mortality at day 42 for the ITT population was $19 \%$ with ISZ (48 patients) and 20\% with VCZ (52 patients), indicating noninferiority of ISZ compared to VCZ. Gastrointestinal complaints were the most common adverse effects reported and were similar in both treatment groups (96\%-98\%). Patients in ISZ arm had a lower frequency of hepatobiliary disorders ( $9 \%$ vs $16 \% ; p=0.016$ ), eye disorders ( $15 \%$ vs $27 \%$; $p=0.002$ ), and cutaneous disorders (33\% vs 42\%; $p=0.037$ ). Overall drug-related adverse events were reported in $42 \%$ of patients receiving ISZ and in $60 \%$ of patients receiving $\mathrm{VCZ}(p<0.001)$. As this trial included patients who had mold infections other than aspergillosis, a subset analysis was performed to evaluate the efficacy of ISZ in patients with IA. Within this subset of 231 patients who had IA, 16\% had proven aspergillosis and $84 \%$ had probable aspergillosis. Hematological malignancy was the most common underlying condition documented in $84 \%$ of patients; $65 \%$ were neutropenic and $20 \%$ had received a hematopoietic stem-cell transplant. For the 231 patients who had proven or probable IA, the all-cause mortality at 42 days was $18.7 \%$ in the ISZ arm and $22.2 \%$ in the VCZ arm. Again the results were similar in the two arms. Treatment success at

Table 3 Drug interactions with ISZ

\begin{tabular}{|c|c|c|c|}
\hline $\begin{array}{l}\text { Drugs that increase serum } \\
\text { ISZ levels }\end{array}$ & $\begin{array}{l}\text { Drugs that decrease serum } \\
\text { ISZ levels }\end{array}$ & $\begin{array}{l}\text { Serum drug levels increased } \\
\text { by ISZ }\end{array}$ & $\begin{array}{l}\text { Serum drug levels } \\
\text { decreased by ISZ }\end{array}$ \\
\hline Ritonavir & Rifampin & Sirolimus & Bupropion \\
\hline Lopinavir/Ritonavir & Rifabutin & Tacrolimus & Lopinavir/ritonavir \\
\hline Effavirenz & Phenytoin & Cyclosporine & \\
\hline \multirow[t]{6}{*}{ Ketoconazole (contraindicated) } & Carbamazepine & Mycophenolate mofetil & \\
\hline & St John's Wort & Digoxin & \\
\hline & Long-acting barbiturates & Colchicine & \\
\hline & & Dabigatran & \\
\hline & & Atorvastatin (mild) & \\
\hline & & Midazolam (mild) & \\
\hline
\end{tabular}

Note: Data from..$^{71-78,87}$

Abbreviation: ISZ, isavuconazole.

Infection and Drug Resistance 2016:9

submit your manuscript | www.dovepress.com 
the end of treatment (35\% vs 38.9\%) was comparable between the ISZ and VCZ arms. The trial concluded that ISZ was noninferior to VCZ for the treatment of invasive mold infections including IA, had a better tolerability and safety profile compared with VCZ, and the data support the use of ISZ as primary therapy for IA. ${ }^{88}$

\section{ISZ for mucormycosis (VITAL trial)}

Given the infrequent occurrence of invasive mucormycosis and other rare molds, and the high mortality associated with these infections, this study was difficult to perform. As expected, enrollment was modest in this nonrandomized clinical trial. This was a noncomparator, single-arm, open-label, matched, case-control trial that evaluated the efficacy of ISZ, and the results were compared with a database of similarly infected patients treated with a polyene. This study allowed both primary treatment of invasive mold infections and salvage treatment of patients who were intolerant of or failing prior antifungal therapy. The study recruited adult patients from 34 centers around the world, from April 2008 to April 2013. Patients were treated with ISZ $200 \mathrm{mg}$ (as its intravenous or oral water-soluble prodrug, isavuconazonium sulfate) three times daily for six doses, followed by $200 \mathrm{mg}$ /day until invasive fungal disease resolution, failure, or for 180 days or more. ISZ was given as primary therapy, or in patients intolerant of prior therapy, it was administered as salvage therapy. A total of 149 patients were enrolled in the study, of which 37 patients had proven $(86 \%)$ or probable (14\%) invasive mucormycosis. Out of these 37 patients, 21 patients had not received prior antifungal therapy, 11 patients had refractory disease, and 5 were intolerant to prior antifungal therapy. The underlying conditions seen in these 37 patients were hematological malignancy (59\%), allogenic stem-cell transplant (35\%), and neutropenia (27\%); only 4/37 patients had diabetes as a major risk factor; $22 / 37$ patients presented with pneumonia (59\%), and half of the patients with pulmonary involvement also had sinus, ocular, or central nervous system infection. The median duration of treatment with ISZ was 84 days (range of 2-882 days).

Cases of mucormycosis treated with ISZ as primary treatment were matched with controls from the Fungiscope Registry, recruited from 17 centers worldwide. Controls received AMB-based treatment. The primary endpoint was all-cause mortality at day 42, and overall response (treatment success or failure) at day 42 , as determined by an independent data review committee based on prespecified criteria. The all-cause mortality at day 42 was $38 \%$. Mortality was higher among patients who had refractory disease or were intolerant to prior therapy (43.7\%), compared with those who were treated for primary mucormycosis $(33.3 \%)$. The overall response rate at day 42 was $31.4 \%$. A matched case-control analysis was performed comparing the 21 patients who had primary treatment with ISZ with the cases of 33 patients who were treated with AMB and whose data had been entered into the global Fungiscope Registry, an ongoing observational database. Matching was done by severity of infection, hematologic malignancy, and whether surgical debridement was performed. In this analysis, ISZ-treated and AMB-treated patients had similar mortality (33.3\% vs 41.3\%, respectively). Assessment of these 37 patients on day 42 showed partial response in $4(11 \%)$, stable disease in $16(43 \%)$, disease progression in $1(3 \%)$, missing assessments in $3(8 \%)$, and 13 patients had died (35\%). The all-cause crude mortality at day 42 was 7 out of 21 (33\%) in the ISZ-treated patients, compared to 13 of $33(39 \%)$ AMB-treated, matched controls. The study concluded that the clinical efficacy and tolerability of ISZ were similar to that of AMB against mucormycosis. The US FDA approved use of ISZ for invasive mucormycosis based on the above data. ${ }^{89}$

\section{ISZ for the treatment of candidemia and invasive candidiasis (ACTIVE trial)}

This was a phase III, randomized, double-blind multinational clinical trial that evaluated the safety and efficacy of ISZ compared with CFG followed by oral VCZ. Patients with proven candidemia or invasive candidiasis were randomized (1:1) to ISZ (200 mg IV TID for 2 days, followed by $200 \mathrm{mg}$ IV QD) or CFG (70 mg IV QD on day 1, followed by $50 \mathrm{mg}$ IV QD) for a maximum of 56 days. A total of 450 patients were randomized; 400 patients comprised the modified ITT population. After 10 days of treatment, patients were switched to oral ISZ (ISZ arm) or VCZ (CFG arm). Primary efficacy endpoint was successful overall response (based on successful clinical and mycological responses as evaluated by an independent Data-Review Committee) at the end of intravenous therapy in patients with proven infection who received $\geq 1$ dose of study drug (modified intent-to-treat population). The prespecified noninferiority margin was set at $15 \%$. The secondary outcome was measured by an assessment of overall response at the end of treatment +2 weeks. All-cause mortality at Days 14 and 56 and safety were also assessed. The primary endpoint of successful overall response at the end of intravenous therapy was $60.3 \%$ in the ISZ arm and $71.1 \%$ in the CFG arm. The results did not meet the noninferiority margin and hence did not meet the primary endpoint. The key secondary endpoint, overall response at the end of intravenous therapy +2 weeks ( $54.8 \%$ for ISZ vs $57.2 \%$ for CFG), was similar in both arms. The all-cause mortality was also similar in both arms (14.6\% ISZ vs $12.4 \%$ CFG). Both drugs were safe and well tolerated. On the basis of the findings mentioned above, ISZ 
is not currently approved for the treatment of candidemia or invasive candidiasis. ${ }^{90}$

\section{Endemic fungi (VITAL study)}

ISZ demonstrated good clinical activity against cryptococcosis, histoplasmosis, coccidioidomycosis, paracoccidioidomycosis, and blastomycosis and serves as a valuable alternative to currently available antifungal agents. ${ }^{91}$

\section{Safety data}

Preclinical in vivo assays for evaluation of safety and mutagenicity were performed in rat and rabbit models. ISZ at systemic exposures below the therapeutic level was associated with a dose-dependent increase in skeletal abnormalities (rudimentary supernumerary ribs, zygomatic arch fusion, etc. in offspring). Administration of isavuconazonium sulfate to rats at a dose of $90 \mathrm{mg} / \mathrm{kg} /$ day (2.3-fold the human maintenance dose) during pregnancy through the weaning period showed an increased perinatal mortality of the pups. Studies using 14C-labeled isavuconazonium sulfate to lactating rats demonstrated excretion of radiolabeled drug in the milk. ISZ did not affect the fertility of male or female rats treated with oral doses up to $90 \mathrm{mg} / \mathrm{kg} /$ day (2.3-fold the clinical maintenance dose based on $\mathrm{mg} / \mathrm{m}^{2} /$ day comparisons). It was not shown to possess mutagenic or genotoxic properties, although specific carcinogenicity studies have not been performed. ISZ had some nonspecific inhibition of the hERG potassium channel and the L-type calcium channel. The in vivo 39-week repeated-dose toxicology studies in monkeys did not show QTc prolongation (unlike other triazoles) at doses up to $40 \mathrm{mg} / \mathrm{kg} /$ day. These preclinical in vivo studies did not indicate any major side effects with ISZ, other than caution in pregnancy. There are reports of QTc shortening with ISZ. Although the clinical significance of ISZ-induced QTc shortening is unknown, it would be reasonable to avoid ISZ in patients with familial short QT syndrome. Also, caution is warranted during the coadministration of ISZ with drugs known to shorten the QT interval (eg, lamotrigine, primidone, rufinamide).${ }^{87}$

\section{Conclusion}

Several in vitro/in vivo evaluations, safety/tolerability data, and results from phase III clinical trials have shown ISZ to have favorable PK and pharamacodynamic profile, and good clinical efficacy with few side effects or drug interactions as compared with available azoles and other antifungal agents (Table 4). The drug has been approved by the US FDA for the

Table 4 Advantages of ISZ over other available triazole agents

\begin{tabular}{|c|c|c|c|c|}
\hline Characteristic & ISZ $^{86,87}$ & POS $^{78,79}$ & $\mathrm{VCZ}^{80-84}$ & Itraconazole 85,86 \\
\hline $\begin{array}{l}\text { Anti-aspergillus and } \\
\text { mucorales activity }\end{array}$ & Aspergillus + mucorales & Aspergillus + mucorales & Aspergillus & Aspergillus \\
\hline Formulation & Oral/IV & Oral/IV & Oral/IV & Oral/IV \\
\hline Oral bioavailability & Equivalent to intravenous & $\begin{array}{l}\text { Depends on dosing frequency } \\
\text { and food (range of } 8 \%-47 \% \text { ) }\end{array}$ & $90 \%-95 \%$ & $\begin{array}{l}30 \% \text { tablet } \\
50 \% \text { solution }\end{array}$ \\
\hline $\begin{array}{l}\text { Food requirement for } \\
\text { absorption }\end{array}$ & Not required & $\begin{array}{l}\text { Increased absorption (with a } \\
\text { fatty meal) }\end{array}$ & $\begin{array}{l}\text { Decreased absorption (with } \\
\text { a fatty meal) }\end{array}$ & $\begin{array}{l}\text { Increased absorption } \\
\text { with acidity }\end{array}$ \\
\hline Kinetics & Linear and predictable & Nonlinear & Nonlinear & Nonlinear \\
\hline Interpatient variability & Minimal & Significant & Significant & Significant \\
\hline Half-life $\left(t_{1 / 2}\right)$ & $56-104 \mathrm{~h}$ & $24-30 \mathrm{~h}$ & $16-35 \mathrm{~h}$ & $24-30 \mathrm{~h}$ \\
\hline Cyclodextrin (for solubility) & Not required & Not required & Required & Not required \\
\hline $\begin{array}{l}\text { Cyp450 effects (resulting in } \\
\text { multiple drug interactions) }\end{array}$ & Minimal (Сур3A4) & $\begin{array}{l}\text { Moderate (Сур3А4, Сур2С9, } \\
\text { Сур2С 19) }\end{array}$ & $\begin{array}{l}\text { High (Сур3А4, Сур2С8, } \\
\text { Сур2С9, Сур2С19, Сур2D) }\end{array}$ & $\begin{array}{l}\text { High (Сур3А4, } \\
\text { Сур2С9, Сур2С 19) }\end{array}$ \\
\hline Food intake & Not required & Better absorption & Better absorption & Better absorption \\
\hline $\begin{array}{l}\text { Antacids/proton pump } \\
\text { inhibitors }\end{array}$ & No change & Decreased level & Decreased & Decreased \\
\hline Renal toxicity & None & None & $\begin{array}{l}\text { Reported with intravenous } \\
\text { formulation }\end{array}$ & None \\
\hline Phototoxicity & None & None & Reported & Reported \\
\hline Skin cancer & None & None & Reported & None \\
\hline Neurological effects & Minimal & $\begin{array}{l}\text { Sensorimotor, mono- and } \\
\text { polyneuropathy }\end{array}$ & $\begin{array}{l}\text { Sensorimotor, mono- and } \\
\text { polyneuropathy }\end{array}$ & $\begin{array}{l}\text { Sensorimotor, mono- } \\
\text { and polyneuropathy }\end{array}$ \\
\hline Visual toxicity & None & Hallucinations & Hallucinations & Hallucinations \\
\hline QTc interval & Shortening (significance unknown) & Prolongation & Prolongation & Prolongation \\
\hline Hepatobiliary & $\begin{array}{l}\text { No data in patients with severe } \\
\text { liver impairment }\end{array}$ & Reported & Reported & Reported \\
\hline With warfarin & No interaction & Prolonged PT/INR & Prolonged PT/INR & Prolonged PT/INR \\
\hline
\end{tabular}

Abbreviations: ISZ, isavuconazole; POS, posaconazole; VCZ, voriconazole; PT, prothrombin time; INR, international normalized ratio. 
management of both IA and mucormycosis. Data on primary therapy for mucormycosis are based on limited data. The drug is not approved for the treatment of candidemia or invasive candidiasis. The availability of oral and parenteral formulations that are bioequivalent is an added benefit. Clinical case reports postapproval are scarce at this time. ${ }^{92-94}$ In addition, given the emergence of azole-resistant strains of aspergillus with differential susceptibility pattern, susceptibility testing of mold isolates may be required in some clinical settings. Likewise, although not required now, therapeutic drug monitoring may be indicated in selected circumstances. With a broad spectrum of anti-mold activity, excellent tolerability, safety, and availability in oral and intravenous formulations, ISZ is likely to be used inappropriately in empiric and prophylactic settings. Although the drug appears promising, caution is warranted before implementing widespread use, until more data become available.

\section{Disclosure}

Dr Chandrasekar is a speaker for Astellas Inc and has received research support. Dr Krishnan Natesan reports no conflicts of interest in this work.

\section{References}

1. Kontoyiannis DP, Marr KA, Park BJ, et al. Prospective surveillance for invasive fungal infections in hematopoietic stem cell transplant recipients, 2001-2006: overview of the transplant-associated infection surveillance network (TRANSNET) database. Clin Infect Dis. 2010;50(8):1091-1100.

2. Pappas PG, Alexander BD, Andes DR, et al. Invasive fungal infections among organ transplant recipients: results of the transplant-associated infection surveillance network (TRANSNET). Clin Infect Dis. 2010;50(8):1101-1111.

3. Neofytos D, Treadway S, Ostrander D, et al. Epidemiology, outcomes, and mortality predictors of invasive mold infections among transplant recipients: a 10-year, single-center experience. Transpl Infect Dis. 2013;15(3):233-242.

4. Kurosawa M, Yonezumi M, Hashino S, et al. Epidemiology and treatment outcome of invasive fungal infections in patients with hematological malignancies. Int J Hematol. 2012;96(6):748-757.

5. Klingspor L, Saaedi B, Ljungman P, Szakos A. Epidemiology and outcomes of patients with invasive mould infections: a retrospective observational study from a single centre (2005-2009). Mycoses. 2015;58(8):470-477.

6. Corzo-León DE, Satlin MJ, Soave R, Shore TB, Schuetz AN, Jacobs SE, Walsh TJ. Epidemiology and outcomes of invasive fungal infections in allogeneic haematopoietic stem cell transplant recipients in the era of antifungal prophylaxis: a single-centre study with focus on emerging pathogens. Mycoses.2015;58(6):325-336.

7. Chamilos G, Luna M, Lewis RE, et al. Invasive fungal infections in patients with hematologic malignancies in a tertiary care cancer center: an autopsy study over a 15-year period (1989-2003). Haematologica. 2006;91(7):986-989.

8. Hong HL, Lee YM, Kim T, et al. Risk factors for mortality in patients with invasive mucormycosis. Infect Chemother. 2013;45(3):292-298.

9. Montagna MT, Lovero G, Coretti C, et al. SIMIFF study: Italian fungal registry of mold infections in hematological and non-hematological patients. Infection. 2014;42(1):141-151.

10. Xhaard A, Lanternier F, Porcher R, et al. Mucormycosis after allogeneic haematopoietic stem cell transplantation: a French Multicentre Cohort Study (2003-2008). Clin Microbiol Infect. 2012;18(10):E396-E400.
11. López-Medrano F, Fernández-Ruiz M, Silva JT, et al. Clinical presentation and determinants of mortality of invasive pulmonary aspergillosis in kidney transplant recipients: a multinational cohort study. $\mathrm{Am} J$ Transplant. 2016;16(11):3220-3234.

12. Trief D, Gray ST, Jakobiec FA, et al. Invasive fungal disease of the sinus and orbit: a comparison between mucormycosis and Aspergillus. $\mathrm{Br} J$ Ophthalmol. 2016;100(2):184-188.

13. Patterson TF, Thompson GR 3rd, Denning DW, et al. Executive summary: practice guidelines for the diagnosis and management of aspergillosis: 2016 update by the infectious diseases society of America. Clin Infect Dis. 2016;63(4):433-442.

14. Abidi MZ, Sohail MR, Cummins N, et al. Stability in the cumulative incidence, severity and mortality of 101 cases of invasive mucormycosis in high-risk patients from 1995 to 2011: a comparison of eras immediately before and after the availability of voriconazole and echinocandinamphotericin combination therapies. Mycoses. 2014;57(11):687-698.

15. Pagano L, Cornely OA, Busca A, et al. Combined antifungal approach for the treatment of invasive mucormycosis in patients with hematologic diseases: a report from the SEIFEM and FUNGISCOPE registries. Haematologica. 2013;98(10):e127-e130.

16. Lerolle N, Raffoux E, Socie G, et al. Breakthrough invasive fungal disease in patients receiving posaconazole primary prophylaxis: a 4-year study. Clin Microbiol Infect. 2014;20(11):O952-O959.

17. Tacke D, Koehler P, Markiefka B, Cornely OA. Our 2014 approach to mucormycosis. Mycoses. 2014;57(9):519-524.

18. Verweij PE, Chowdhary A, Melchers WJ, Meis JF. Azole Resistance in Aspergillus fumigatus: can we retain the clinical use of mold-active antifungal azoles? Clin Infect Dis. 2016;62(3):362-368.

19. Ananda-Rajah MR, Kontoyiannis D. Isavuconazole: a new extended spectrum triazole for invasive mold diseases. Future Microbiol. 2015; 10(5):693-708.

20. Pettit NN, Carver PL. Isavuconazole: a new option for the management of invasive fungal infections. Ann Pharmacother. 2015;49(7):825-842.

21. McCormack PL. Isavuconazonium: first global approval. Drugs. 2015;75(7):817-822.

22. Roilides E, Antachopoulos C. Isavuconazole: an azole active against mucormycosis. Lancet Infect Dis. 2016;16(7):761-762.

23. Kovanda LL, Maher R, Hope WW. Isavuconazonium sulfate: a new agent for the treatment of invasive aspergillosis and invasive mucormycosis. Expert Rev Clin Pharmacol. 2016;9(7):887-897.

24. Graves B, Morrissey CO, Wei A, et al. ISZ as salvage therapy for mucormycosis. Med Mycol Case Rep. 2016;11:36-39.

25. Donnelley MA, Zhu ES, Thompson GR 3rd. Isavuconazole in the treatment of invasive aspergillosis and mucormycosis infections. Infect Drug Resist. 2016;9:79-86.

26. Walker RC, Zeuli JD, Temesgen Z. Isavuconazonium sulfate for the treatment of fungal infection. Drugs Today (Barc). 2016;52(1):7-16.

27. Miceli MH, Kauffman CA. Isavuconazole: a new broad-spectrum triazole antifungal agent. Clin Infect Dis. 2015;61(10):1558-1565.

28. Chitasombat MN, Kontoyiannis DP. The 'cephalosporin era' of triazole therapy: isavuconazole, a welcomed newcomer for the treatment of invasive fungal infections. Expert Opin Pharmacother. 2015;16(10): $1543-1558$

29. Ananda-Rajah MR, Kontoyiannis D. Isavuconazole: a new extended spectrum triazole for invasive mold diseases. Future Microbiol. 2015;10(5): 693-708.

30. Falci DR, Pasqualotto AC. Profile of isavuconazole and its potential in the treatment of severe invasive fungal infections. Infect Drug Resist. 2013; 6:163-174.

31. Slavin MA, Thursky KA. Isavuconazole: a role for the newest broadspectrum triazole. Lancet. 2016;387(10020):726-728.

32. Guinea J, Bouza E. Isavuconazole: a new and promising antifungal triazole for the treatment of invasive fungal infections. Future Microbiol. 2008;3(6):603-615.

33. Chowdhary A, Singh PK, Kathuria S, Hagen F, Meis JF. Comparison of the EUCAST and CLSI broth microdilution methods for testing isavuconazole, posaconazole, and amphotericin B against molecularly identified mucorales species. Antimicrob Agents Chemother. 2015;59(12):7882-7887. 
34. Arendrup MC, Howard S, Lass-Flörl C, Mouton JW, Meletiadis J, Cuenca-Estrella M. EUCAST testing of Isavuconazole susceptibility in Aspergillus: comparison of results for Inoculum standardization using Conidium counting versus optical density. Antimicrob Agents Chemother. 2014;58(11):6432-6436.

35. Box H, Livermore J, Johnson A, et al. Pharmacodynamics of Isavuconazole in a Dynamic in vitro model of invasive pulmonary aspergillosis. Antimicrob Agents Chemother. 2015;60(1):278-287.

36. Gregson L, Goodwin J, Johnson A, et al. In vitro susceptibility of Aspergillus fumigatus to Isavuconazole: correlation with itraconazole, voriconazole, and posaconazole. Antimicrob Agents Chemother. 2013; 57(11):5778-5780.

37. Chowdhary A, Kathuria S, Randhawa HS, Gaur SN, Klaassen CH, Meis JF. Isolation of multiple-triazole-resistant Aspergillus fumigatus strains carrying the TR/L98H mutations in the cyp51A gene in India. J Antimicrob Chemother. 2012;67(2):362-366.

38. Pfaller MA, Messer SA, Rhomberg PR, Jones RN, Castanheira M. In vitro activities of Isavuconazole and comparator antifungal agents tested against a global collection of opportunistic yeasts and molds. $J$ Clin Microbiol. 2013;51(8):2608-2616.

39. Shivaprakash MR, Geertsen E, Chakrabarti A, Mouton JW, Meis JF. In vitro susceptibility of 188 clinical and environmental isolates of Aspergillus flavus for the new triazole Isavuconazole and seven other antifungal drugs. Mycoses. 2011;54(5):e583-e589.

40. Rudramurthy SM, Chakrabarti A, Geertsen E, Mouton JW, Meis JF. In vitro activity of isavuconazole against 208 Aspergillus flavus isolates in comparison with 7 other antifungal agents: assessment according to the methodology of the European Committee on Antimicrobial Susceptibility Testing. Diagn Microbiol Infect Dis. 2011;71(4):370-377.

41. Espinel-Ingroff A, Chowdhary A, Gonzalez GM, et al. Multicenter study of isavuconazole MIC distributions and epidemiological cutoff values for Aspergillus spp. for the CLSI M38-A2 broth microdilution method. Antimicrob Agents Chemother. 2013;57(8):3823-3828.

42. Verweij PE, González GM, Wiedrhold NP, et al. In vitro antifungal activity of isavuconazole against 345 mucorales isolates collected at study centers in eight countries. J Chemother. 2009;21(3):272-281.

43. Warn PA, Sharp A, Denning DW. In vitro activity of a new triazole BAL4815, the active component of BAL8557 (the water-soluble prodrug), against Aspergillus spp. J Antimicrob Chemother. 2006;57(1):135-138.

44. Perkhofer S, Lechner V, Lass-Flörl C; European Committee on Antimicrobial Susceptibility Testing. In vitro activity of isavuconazole against Aspergillus species and zygomycetes according to the methodology of the European Committee on Antimicrobial Susceptibility Testing. Antimicrob Agents Chemother. 2009;53(4):1645-1647.

45. Guinea J, Peláez T, Recio S, Torres-Narbona M, Bouza E. In vitro antifungal activities of isavuconazole (BAL4815), VCZ, and fluconazole against 1,007 isolates of zygomycete, Candida, Aspergillus, Fusarium, and Scedosporium species. Antimicrob Agents Chemother. 2008;52(4):1396-1400. Erratum in: Antimicrob Agents Chemother. 2008; 52(11):4211.

46. Arendrup MC, Jensen RH, Meletiadis J. In vitro activity of isavuconazole and comparators against clinical isolates of the mucorales order. Antimicrob Agents Chemother. 2015;59(12):7735-7742.

47. Pfaller MA, Rhomberg PR, Messer SA, Jones RN, Castanheira M. Isavuconazole, MFG, and 8 comparator antifungal agents' susceptibility profiles for common and uncommon opportunistic fungi collected in 2013: temporal analysis of antifungal drug resistance using CLSI species-specific clinical breakpoints and proposed epidemiological cutoff values. Diagn Microbiol Infect Dis. 2015;82(4):303-313.

48. Katragkou A, McCarthy M, Meletiadis J, et al. In vitro combination of isavuconazole with micafungin or amphotericin B deoxycholate against medically important molds. Antimicrob Agents Chemother. 2014;58(11): 6934-6937.

49. Seyedmousavi S, Brüggemann RJ, Meis JF, Melchers WJ, Verweij PE, Mouton JW. Pharmacodynamics of isavuconazole in an Aspergillus fumigatus mouse infection model. Antimicrob Agents Chemother. 2015; 59(5):2855-2866.
50. Schmitt-Hoffman A, Richter WF. Isavuconazole is widely distributed in rat tissue. ECCMID. March 31-April 3, 2012; London, UK. Poster number P863.

51. Andes D, Pascual A, Marchetti O. Antifungal therapeutic drug monitoring: established and emerging indications. Antimicrob Agents Chemother. 2009;53(1):24-34.

52. Luo G, Gebremariam T, Lee H, Edwards JE Jr, Kovanda L, Ibrahim AS. Isavuconazole therapy protects immunosuppressed mice from mucormycosis. Antimicrob Agents Chemother. 2014;58(4):2450-2453.

53. Lepak AJ, Marchillo K, Vanhecker J, Andes DR. Isavuconazole (BAL4815) pharmacodynamic target determination in an in vivo murine model of invasive pulmonary aspergillosis against wild-type and cyp51 mutant isolates of Aspergillus fumigatus. Antimicrob Agents Chemother. 2013;57(12):6284-6289.

54. Desai A, Schmitt-Hoffmann AH, Mujais S, Townsend R. Population pharmacokinetics of isavuconazole in subjects with mild or moderate hepatic impairment. Antimicrob Agents Chemother. 2016;60(5):3025-3031.

55. Schmitt-Hoffmann A, Roos B, Spickermann J, Heep M, Peterfaí E, Edwards DJ, Stoeckel K. Effect of mild and moderate liver disease on the pharmacokinetics of isavuconazole after intravenous and oral administration of a single dose of the prodrug BAL8557. Antimicrob Agents Chemother. 2009;53(11):4885-4890.

56. Livermore J, Hope W. Evaluation of the pharmacokinetics and clinical utility of isavuconazole for treatment of invasive fungal infections. Expert Opin Drug Metab Toxicol. 2012;8(6):759-765.

57. Thompson GR3rd, Wiederhold NP. Isavuconazole: a comprehensive review of spectrum of activity of a new triazole. Mycopathologia. 2010;170(5): 291-313.

58. Warn PA, Sharp A, Parmar A, Majithiya J, Denning DW, Hope WW. Pharmacokinetics and pharmacodynamics of a novel triazole, isavuconazole: mathematical modeling, importance of tissue concentrations, and impact of immune status on antifungal effect. Antimicrob Agents Chemother. 2009;53(8):3453-3461

59. Schmitt-Hoffmann A, Roos B, Maares J, et al. Multiple-dose pharmacokinetics and safety of the new antifungal triazole BAL4815 after intravenous infusion and oral administration of its prodrug, BAL8557, in healthy volunteers. Antimicrob Agents Chemother. 2006;50(1):286-293.

60. Schmitt-Hoffmann A, Roos B, Heep M, et al. Single-ascending-dose pharmacokinetics and safety of the novel broad-spectrum antifungal triazole BAL4815 after intravenous infusions (50,100, and 200 milligrams) and oral administrations (100, 200, and 400 milligrams) of its prodrug, BAL8557, in healthy volunteers. Antimicrob Agents Chemother. 2006;50(1):279-285.

61. Courtney R, Pai S, Laughlin M, Lim J, Batra V. Pharmacokinetics, safety, and tolerability of oral posaconazole administered in single and multiple doses in healthy adults. Antimicrob Agents Chemother. 2003; 47(9):2788-2795.

62. Rybak JM, Marx KR, Nishimoto AT, Rogers PD. Isavuconazole: Pharmacology, pharmacodynamics, and current clinical experience with a new triazole antifungal agent. Pharmacotherapy. 2015;35(11): 1037-1051.

63. Kovanda LL, Petraitiene R, Petraitis V, et al. Pharmacodynamics of isavuconazole in experimental invasive pulmonary aspergillosis: implications for clinical breakpoints. J Antimicrob Chemother. 2016;71(7): 1885-1891.

64. Petraitis V, Petraitiene R, Moradi PW, et al. Pharmacokinetics and concentration-dependent efficacy of isavuconazole for treatment of experimental invasive pulmonary aspergillosis. Antimicrob Agents Chemother. 2016;60(5):2718-2726.

65. Cornely OA, Böhme A, Schmitt-Hoffmann A, Ullmann AJ. Safety and pharmacokinetics of isavuconazole as antifungal prophylaxis in acute myeloid leukemia patients with neutropenia: results of a phase 2 , dose escalation study. Antimicrob Agents Chemother. 2015;59(4):2078-2085.

66. Knoll BM. Pharmacokinetics of oral isavuconazole in a patient after Roux-en-Y gastric bypass surgery. J Antimicrob Chemother. 2014; 69(12):3441-3443. 
67. Desai A, Kovanda L, Kowalski D, Lu Q, Townsend R, Bonate PL. Population pharmacokinetics of isavuconazole from Phase 1 and Phase 3 (SECURE) trials in adults and target attainment in patients with invasive infections due to aspergillus and other filamentous fungi. Antimicrob Agents Chemother. 2016;60(9):5483-5491.

68. Schmitt-Hoffmann A, Desai A, Kowalski D, Pearlman H, Yamazaki T, Townsend R. Isavuconazole absorption following oral administration in healthy subjects is comparable to intravenous dosing, and is not affected by food, or drugs that alter stomach $\mathrm{pH}$. Int J Clin Pharmacol Ther. 2016;54(8):572-580.

69. Kovanda LL, Desai AV, Lu Q, Townsend RW, Akhtar S, Bonate P, Hope WW.. Isavuconazole population pharmacokinetic analysis using non-parametric estimation in patients with invasive fungal disease: results from the VITAL study. Antimicrob Agents Chemother. 2016; 60(8):4568-4576.

70. Horn D, Goff D, Khandelwal N, et al. Hospital resource use of patients receiving isavuconazole vs voriconazole for invasive mold infections in the phase III SECURE trial. J Med Econ. 2016;19(7):728-734.

71. Desai A, Yamazaki T, Dietz AJ, et al. Pharmacokinetic and pharmacodynamic evaluation of the drug-drug interaction between isavuconazole and warfarin in healthy subjects. Clin Pharmacol Drug Dev. Epub 2016 Jun 9.

72. Townsend R, Dietz A, Hale C, et al. Pharmacokinetic evaluation of CYP3A4-mediated drug-drug interactions of ISZ with Rifampin, Ketoconazole, Midazolam, and Ethinyl Estradiol/Norethindrone in healthy adults. Clin Pharmacol Drug Dev. Epub 2016 Jun 8.

73. Groll AH, Desai A, Han D, et al. Pharmacokinetic assessment of drugdrug interactions of isavuconazole with the immunosuppressants Cyclosporine, Mycophenolic Acid, Prednisolone, Sirolimus, and Tacrolimus in healthy adults. Clin Pharmacol Drug Dev. Epub 2016 Jun 8.

74. Yamazaki T, Desai A, Han D, et al. Pharmacokinetic interaction between isavuconazole and a fixed-dose combination of lopinavir $400 \mathrm{mg}$ / Ritonavir $100 \mathrm{mg}$ in healthy subjects. Clin Pharmacol Drug Dev. Epub 2016 Jun 8.

75. Yamazaki T, Desai A, Goldwater R, et al. Pharmacokinetic effects of isavuconazole Co-administration with the cytochrome P450 enzyme substrates Bupropion, Repaglinide, Caffeine, Dextromethorphan, and Methadone in healthy subjects. Clin Pharmacol Drug Dev. Epub 2016 Jun 8.

76. Yamazaki T, Desai A, Goldwater R, et al. Pharmacokinetic interactions between isavuconazole and the drug transporter substrates atorvastatin, digoxin, metformin, and methotrexate in healthy subjects. Clin Pharmacol Drug Dev. Epub 2016 Jun 8.

77. Kim T, Jancel T, Kumar P, Freeman AF. Drug-drug interaction between Isavuconazole and tacrolimus: a case report indicating the need for tacrolimus drug-level monitoring. J Clin Pharm Ther. Epub 2015 Aug 6.

78. Dolton MJ, Ray JE, Marriott D, McLachlan AJ. Posaconazole exposureresponse relationship: evaluating the utility of therapeutic drug monitoring. Antimicrob Agents Chemother. 2012;56(6):2806-2813.

79. Greer ND. Posaconazole (Noxafil): a new triazole antifungal agent. Proc (Bayl Univ Med Cent). 2007;20(2):188-196.
80. Levêque D, Nivoix Y, Jehl F, Herbrecht R. Clinical pharmacokinetics of voriconazole. Int J Antimicrob Agents. 2006;27(4):274-284.

81. Moton A, Krishna G, Ma L, et al. Pharmacokinetics of a single dose of the antifungal posaconazole as oral suspension in subjects with hepatic impairment. Curr Med Res Opin. 2010;26(1):1-7.

82. Williams K, Mansh M, Chin-Hong P, Singer J, Arron ST. VCZ-associated cutaneous malignancy: a literature review on photocarcinogenesis in organ transplant recipients. Clin Infect Dis. 2014;58(7):997-1002.

83. Boyd AE, Modi S, Howard SJ, Moore CB, Keevil BG, Denning DW. Adverse reactions to voriconazole. Clin Infect Dis. 2004;39(8): 1241-1244.

84. Luong ML, Al-Dabbagh M, Groll AH, Racil Z, Nannya Y, Mitsani D, Husain S.. Utility of voriconazole therapeutic drug monitoring: a metaanalysis. J Antimicrob Chemother. 2016;71(7):1786-1799.

85. Lestner J, Hope WW. Itraconazole: an update on pharmacology and clinical use for treatment of invasive and allergic fungal infections. Expert Opin Drug Metab Toxicol. 2013;9(7):911-926.

86. Lestner JM, Roberts SA, Moore CB, Howard SJ, Denning DW, Hope WW. Toxicodynamics of itraconazole: implications for therapeutic drug monitoring. Clin Infect Dis. 2009;49(6):928-930.

87. Advisory Committee Briefing Document. Isavuconazonium: Invasive Aspergillosis and Invasive Mucormycosis; 2015. Available from: http://www.fda.gov/downloads/AdvisoryCommittees/CommitteesMeetingMaterials/Drugs/Anti-InfectiveDrugsAdvisoryCommittee/ UCM430747.pdf. Accessed August 2016.

88. Maertens JA, Raad II, Marr KA, et al. Isavuconazole versus voriconazole for primary treatment of invasive mould disease caused by Aspergillus and other filamentous fungi (SECURE): a phase 3, randomisedcontrolled, non-inferiority trial. Lancet. 2016;387(10020):760-769.

89. Marty FM, Ostrosky-Zeichner L, Cornely OA, et al; VITAL and Fungiscope Mucormycosis Investigators. ISZ treatment for mucormycosis: a single-arm open-label trial and case-control analysis. Lancet Infect Dis. 2016;16(7):828-837.

90. National Institutes of Health Isavuconazole (BAL8557) in the treatment of candidemia and other invasive Candida infections ClinicalTrials. gov [website on the Internet] Bethesda, MD: US National Library of Medicine; 2013. Available from: http://www.clinicaltrials.gov/ct2/show/ NCT00413218. Accessed August 2016.

91. Thompson GR 3rd, Rendon A, Ribeiro Dos Santos R, et al. Isavuconazole treatment of cryptococcosis and dimorphic mycoses. Clin Infect Dis. 2016;63(3):356-362.

92. Ahmed Y, Delaney S, Markarian A. Successful isavuconazole therapy in a patient with acute invasive fungal rhinosinusitis and acquired immune deficiency syndrome. Am J Otolaryngol. 2016;37(2):152-155.

93. Peixoto D, Gagne LS, Hammond SP, Gilmore ET, Joyce AC, Soiffer RJ, Marty FM. Isavuconazole treatment of a patient with disseminated mucormycosis. J Clin Microbiol. 2014;52(3):1016-1019.

94. Ervens J, Ghannoum M, Graf B, Schwartz S. Successful isavuconazole salvage therapy in a patient with invasive mucormycosis. Infection. 2014; 42(2):429-432.
Infection and Drug Resistance

\section{Publish your work in this journal}

Infection and Drug Resistance is an international, peer-reviewed openaccess journal that focuses on the optimal treatment of infection (bacterial, fungal and viral) and the development and institution of preventive strategies to minimize the development and spread of resistance. The journal is specifically concerned with the epidemiology of antibiotic resistance and the mechanisms of resistance development and diffusion in both hospitals and the community. The manuscript management system is completely online and includes a very quick and fair peerreview system, which is all easy to use. Visit http://www.dovepress.com testimonials.php to read real quotes from published authors. 